\title{
The Development History of Cathode and Anode Materials of Lithium Ion Battery
}

\author{
Yuanyuan Liu \\ North China Electric Power University Baoding city, Hebei province, China \\ 2191385753@qq.com
}

\begin{abstract}
Keywords: Lithium-ion battery; Cathode and anode materials; Improvement; Development of history
\end{abstract}

\begin{abstract}
Lithium ion battery has a series of significant advantages, such as a low energy consumption, high specific capacity and specific energy, high working voltage, long cycle life, low self discharge, friendly to environment, good cycle performance, long service life and so on . Today it is widely applied in various aspects, such as notebook computers, electric cars, cameras, etc. With the wide application of lithium ion battery, the lithium ion battery performance requirements are higher and higher. High performance of the battery depends on the improvement of the performance of the negative electrode materials and positive electrolyte materials [1]. Battery cathode and anode materials are from the invention of lithium ion battery to now also experience improvement again and again. This paper introduces the lithium ion battery cathode and anode materials the development of history.

Lithium ion battery research began in the $1980 \mathrm{~s}$. Lithium ion battery refers to lithium ion embedded compounds as the anode material of lithium ion battery. Lithium-ion batteries for its advantages much more and more get the welcome of people. The advantages of lithium ion battery performance compared to other battery shown in the following Table 2 .
\end{abstract}

Table 1 Characteristics of Rechargeable Batteries

\begin{tabular}{|c|c|c|c|c|c|c|}
\hline & $\begin{array}{l}\text { Tin nickel } \\
\text { battery }\end{array}$ & $\begin{array}{l}\text { NI-MH } \\
\text { battery }\end{array}$ & $\begin{array}{l}\text { Small } \\
\text { lead-acid } \\
\text { batteries }\end{array}$ & $\begin{array}{l}\text { lithium } \\
\text { battery }\end{array}$ & $\begin{array}{l}\text { lithium } \\
\text { polymer } \\
\text { battery }\end{array}$ & $\begin{array}{l}\text { lithium } \\
\text { polymer } \\
\text { battery }\end{array}$ \\
\hline The energy density $(\mathrm{Wh} / \mathrm{kg})$ & $40-60$ & $60-80$ & 30 & 100 & $150-200$ & 80 \\
\hline Cycle life lost & 1500 & 500 & $200-500$ & $500-1000$ & $100-150$ & $10(65 \%)$ \\
\hline Quick charge time (h) & 1.5 & $2 \sim 4$ & $8 \sim 16$ & $3 \sim 4$ & $8 \sim 15$ & $2 \sim 3$ \\
\hline Monthly self-discharge & $20 \%$ & $30 \%$ & $5 \%$ & $10 \%$ & 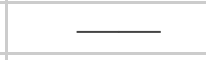 & $0.3 \%$ \\
\hline $\begin{array}{l}\text { The nominal battery voltage } \\
\text { (V) }\end{array}$ & 1.25 & 1.25 & 2 & 3.6 & 2.7 & 1.5 \\
\hline load current & $>2 \mathrm{C}$ & $0.5 \sim 1 \mathrm{C}$ & $0.2 \mathrm{C}$ & $1 \mathrm{C}$ & $0.2 \mathrm{C}$ & $0.2 \mathrm{C}$ \\
\hline Working temperature $\left({ }^{\circ} \mathrm{C}\right)$ & $-40 \sim 60$ & $-20 \sim 60$ & $-20 \sim 60$ & $-20 \sim 60$ & - & $\mathrm{O} \sim 65$ \\
\hline Impact on environment & \multicolumn{2}{|c|}{$\begin{array}{ll}\text { Cadmium, heavy } \\
\text { serious metal } \\
\text { pollution } & \text { pollution }\end{array}$} & $\begin{array}{l}\text { heavy } \\
\text { metal } \\
\text { pollution }\end{array}$ & \multicolumn{3}{|c|}{$\begin{array}{l}\text { heavy metalheavy metalmercury } \\
\text { pollution pollution pollution }\end{array}$} \\
\hline
\end{tabular}

\section{Lithium Ion Batteries Work Principle}

Lithium-ion battery is mainly composed of positive and negative, electrolyte solution and the diaphragm separated by positive and negative. The anode material of the lithium ion battery is lithium-containing compounds such as $\mathrm{LiCoO} 2, \mathrm{LiMn} 2 \mathrm{O} 4$ etc. The cathode material is a carbon material, such as graphite. The electrolyte is an organic solvent of lithium salt. During the charging process, the lithium ions in the positive electrode material begin to migrate from the positive electrode through the diaphragm to the negative direction, and one electron is captured on the 
negative electrode to be reduced to $\mathrm{Li}$ and stored in the graphite having the layered structure. Lithium ions are lost in the negative electrode and become lithium ions in the discharge. Lithium ions migrate through the membrane in the positive direction and stored in the positive electrode material [3]. The reaction mechanism is as follows.

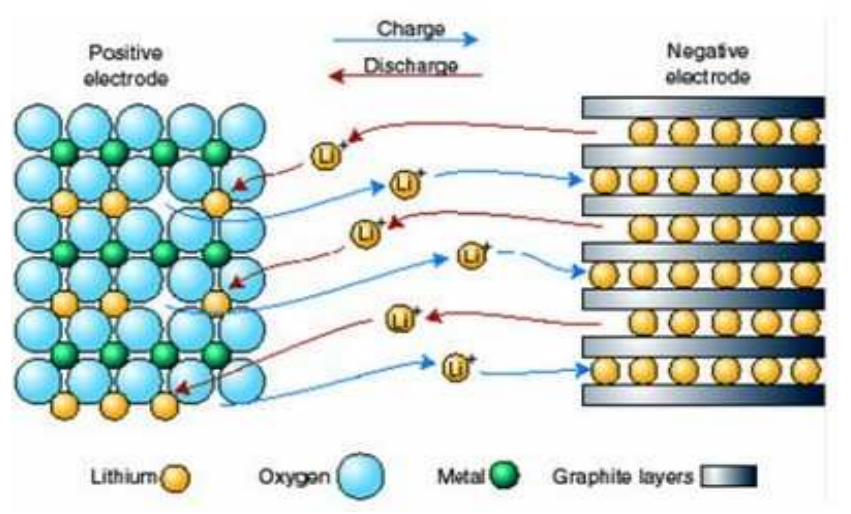

Figure 1.

\section{Lithium ion anode material development process}

Lithium-ion battery anode material improvement is the key to improve the performance of lithium-ion battery. It not only as an electrode material involved in electrochemical reactions, but also provides lithium ions. Lithium-ion battery anode materials research began in the 20th century 80 years. Compared to the negative pole, lithium-ion battery cathode material research is lagging behind. Because its energy density and power density are relatively low, anode materials into lithium-ion battery materials research becomes focus and hotspot [4].

\section{Lithium-ion battery anode material in the past development process}

Lithium ion battery anode material is the first application of $\mathrm{LiCoO}_{2}, \mathrm{LiNiO}_{2}$ and $\mathrm{LiMn}_{2} \mathrm{O}_{4}$ which laid the basis for the study of cathode materials.

LiCoO $\mathrm{LiCoO}_{2}$ is the first commercial anode material, and is still the mainstream of consumer electronics products in the field of anode materials. $\mathrm{LiCoO}_{2}$ has a typical type structure that there are obvious layered material characteristics which is called $\alpha-\mathrm{NaFeO}_{2}$. It has a two-dimensional de-embedding path, high ion conductivity, good magnification discharge performance [5]. Compared with other anode electrode materials, it has high working voltage, stable charge and discharge voltage, suitable for large current charge and discharge, high specific energy, good reversible performance, high charging efficiency, high electrical conductivity, etc. However, due to the toxicity of cobalt, pollution of the environment, lack of resources, and its poor thermal stability, poor anti-overcharge, there is a big security risk, so its safety is a major problem in limiting the application of $\mathrm{LiCoO}_{2}$.

LiNiO ${ }_{2} \cdot \mathrm{LiNiO}_{2}$ has a typical type structure which is called $\alpha-\mathrm{NaFeO}_{2}$. Layered $\mathrm{NiO}_{2}$ provides a two-dimensional tunnel for lithium ions. In the crystal structure of $\mathrm{LiNiO}_{2}, \mathrm{Li}-\mathrm{O}$ is weaker than $\mathrm{Ni}-\mathrm{O}$ which makes it have the characteristics of the ionic bond. Under certain conditions, $\mathrm{Li}^{+}$can be embedded between the layers of $\mathrm{NiO}_{2} . \mathrm{LiNiO}_{2}$ as a lithium-ion battery anode material has low discharge efficiency, low price, no pollution and a series of advantages. However, it has been shown that $\mathrm{LiNiO}_{2}$ undergoes multiple phase transition during $\mathrm{Li}^{+}$desorption, which reduces the cycling performance of lithium ion battery [6].

$\mathbf{L i M n}_{2} \mathbf{O}_{4} \cdot \mathrm{LiMn}_{2} \mathrm{O}_{4}$ material has the advantages of rich natural resources, low cost and environment friendly. So it is considered a kind of lithium ion battery positive electrode material with more development potential. $\mathrm{LiMn}_{2} \mathrm{O}_{4}$ anode material has a unique three-dimensional tunnel structure which is conducive to the battery cycle charge and discharge ions in the material diffusion. However, $\mathrm{LiMn}_{2} \mathrm{O}_{4}$ materials prone to Jahn Teller disruptive effect which is easy to cause the crystal phase transition by vertical direction square crystal phase shift, and makes the material low cycle performance [7]. 


\section{Lithium-ion battery anode material development today}

Currently used and developed lithium battery anode material, the transition metal oxide showed the best performance. It mainly includes layered structure of lithium cobalt oxide $\left(\mathrm{LiCoO}_{2}\right)$, lithium cobalt oxide and Nickel manganese acid lithium ternary material, spinel-structure lithium manganese oxides, olivine-type lithium iron phosphate and other lithium manganese oxide. Since the 21 st century, nickel cobalt manganese acid lithium ternary material ( $\left.\mathrm{Li}(\mathrm{Ni}, \mathrm{Co}, \mathrm{Mn}) \mathrm{O}_{2}\right)$ and layered rich lithium high manganese materials research become a hot spot, including nickel and cobalt ternary manganese acid lithium materials in this century (2001-2011) to achieve the commercialization.

Nickel cobalt manganese acid lithium ternary material.Nickel-cobalt-manganese ternary materials include nickel, cobalt, manganese. Three kinds of metal ratio is different, then some basic properties, such as capacity, theoretical density, safety and structural stability and so on are different.. Nickel is bivalent and is the main electrochemical activity element. Manganese is tetravalent, though not to participate in the electrochemical reaction, only on the material to ensure stability and thermal stability of deconstruction. Cobalt is part is trivalent, participating in the electrochemical reaction. Its main effect is to guarantee material layer structure neat degree, reduce material electrochemical polarization, and improve the rate performance [8]. Nickel cobalt manganese acid lithium ternary material with high specific capacity, high voltage under the advantages of good stability, safety, is one of the most application prospects lithium ion anode materials.

Layered lithium-rich high manganese material.The layered lithium-rich high-manganese material is a lithium-rich manganese-based anode material made of an excess of lithium and manganese in the anode material of a nickel-cobalt-manganese ternary material (LiNi1-x-yMnxCoyO2). This material has more excellent than the original positive material, the cycle performance and stability and low price. Although the lithium-rich material has achieved many results, there are still some problems that constrain its further development: (1) in practical applications, the improvement of material magnification performance or the effect is limited, or the process is complex and expensive (2)the lithium-rich material in the cycle of more than 200 cycles will occur spinel phase transition, resulting in its structure changes, the capacity of a sharp decline, and therefore also limited its commercial applications [9].

\section{Lithium Ion Cathode Material Development Process}

Lithium ion secondary battery research began in the 20th century, 80 years. In 1990, Japan Nagoura developed into a petroleum coke as the negative, $\mathrm{LiCoO} 2$ as the cathode lithium secondary battery. At the same year, Moli and Sony two battery companies claim to launch a carbon-negative lithium-ion battery. In 1991, Japan's Sony Energy Technology Corporation and the battery department jointly developed a polysaccharide alcohol pyrolytic carbon (PFA) as the negative lithium-ion battery. In 1993, Bellcore of the United States first reported the use of PVDF process to produce polymer lithium-ion battery (PLIB).

From the already mature application and research prospects, can be used in lithium battery cathode material has experienced the following stages that can be divided into the following:

The first is a carbon negative material: the current has been actually used for lithium-ion battery cathode materials are basically carbon materials, such as artificial graphite, natural graphite, mesophase carbon microspheres, petroleum coke, carbon fiber, pyrolysis resin .

The second is a lithium-containing transition metal oxide material, such as lithium titanate, which has been implemented in bulk industrialization and applications.

The third is lithium-containing transition metal nitride cathode material, but there are no commercial products.

The fourth is the alloy cathode material: including tin-based alloy, silicon-based alloy, germanium-based alloy aluminum-based alloys, antimony-based alloys, magnesium-based alloys 
and other alloys. In addition to Japan's current small part of the application of high-capacity silicon carbide cathode materials, it has not yet large-scale industrialization.

The fifth is the nano-scale cathode materials and nanometer oxide cathode materials: carbon nanotubes, nano-alloy materials. Such materials are different from all battery system .The lithium battery cathode auxiliary materials is to improve the overall performance of the battery [10].

\section{Conclusion}

Lithium-ion battery performance depends mainly on the structure and performance of positive and negative materials. Since the lithium-ion battery has been invented so far, the performance of positive and negative materials has also become the direction of people's research. With the rapid development of science and technology, I believe in the near future, people will develop a higher performance lithium-ion battery that benefits mankind.

\section{References}

[1] L.Wang, P.Z.Gao, D.Y.Li ,S.Huang and H.N.Xiao.The research progress of lithium ion battery anode material [J]. Journal of silicate bulletin, 2013, (01) : 77-84.

[2] http://www.18650.com.cn/news/15373169.html

[3] B.Ming and H.Y.Han. Lithium ion battery anode material progress [J]. Chemical production and technology, 2012, (4): 24-33 + 66-67.

[4] L.Wang, P.Z.Gao,D.Y.Li ,S.Huang and H.N.Xiao.The research progress of lithium ion battery anode material [J]. Journal of silicate bulletin, 2013, (01): 77-84.

[5] H.X.Guo, Y.C.Qiao and P.Z.Mu. Lithium ion battery anode material research and application progress [J]. Journal of inorganic salt industry, 2016, (3): 5-8 +51.

[6] Q.Z.Xiao. Lithium ion battery anode material of lithium nickel cobalt oxide $(\mathrm{LiNiCo}(0.8)(0.2) \mathrm{O} 2)$ preparation and modification of research [D]. Xiangtan university, 2004

[7] Y.Qi. Lithium ion battery anode material lithium manganese acid electrochemical properties research [D]. Dalian university of technology, 2013

[8] Y.C.Sun. Nickel cobalt manganese acid lithium ternary anode material research and application [J]. Journal of inorganic salt industry, 2014. (01) : 1-3.

[9] H.F.Shang. Lithium ion battery anode materials and the surface of the LiFePO_4 and LiMn_2O_4 structure and electrical chemical properties research [D]. Beijing university of technology, 2013

[10] Y.M .Qiao. Present situation and development trend of lithium ion battery cathode materials [J]. Journal of high technology and industrialization, 2014, (02): 56-61. 